\title{
Landslide Assessment and Monitoring along the Jinsha River, Southwest China, by Combining InSAR and GPS Techniques
}

\author{
Yuanyuan Ma, ${ }^{1,2}$ Fei Li $\mathbb{D}^{1,2}$ Zemin Wang, ${ }^{2}$ Xiaoqing Zou, ${ }^{3}$ Jiachun $\mathrm{An}^{2}$ and Bing $\mathrm{Li}^{2}$ \\ ${ }^{1}$ Electronic Information School, Wuhan University, Wuhan, 430072 Hubei, China \\ ${ }^{2}$ Chinese Antarctic Center of Surveying and Mapping, Wuhan University, Wuhan, 430079 Hubei, China \\ ${ }^{3}$ Kunming University of Science and Technology, Kunming, 650093 Yunnan, China
}

Correspondence should be addressed to Fei Li; feili_wh@163.com

Received 1 September 2021; Accepted 15 January 2022; Published 9 February 2022

Academic Editor: Cong-Bin Fan

Copyright (c) 2022 Yuanyuan Ma et al. This is an open access article distributed under the Creative Commons Attribution License, which permits unrestricted use, distribution, and reproduction in any medium, provided the original work is properly cited.

\begin{abstract}
This paper focuses on ancient landslides located along the Jinsha River between the Ahai hydropower station (AHHs) and Liyuan hydropower station (LYHs). High-precision landslide monitoring and accurate understanding of inducing factors are important for landslide stability analysis. However, it is often difficult to monitor and analyze landslide movement due to rough terrain and the complex inducing factors in the mountain area. In this paper, the ancient landslides can be monitored by distributed scatterers-based interferometric synthetic aperture radar (DS-InSAR) technology and global positioning systems (GPS). DSInSAR can obtain enough measurement points based on the persistent scatterers and distributed scatterers. Besides, we present the results of GPS measurement as a comparison and supplement to DS-InSAR. Our results illustrate that DS-InSAR measurement and GPS measurement show high-level consistency. To comprehensively analyze the triggering factors of landslide deformation, we derive the spatiotemporal movement characteristics of the XinJian (XJ) landslide and find that the $\mathrm{XJ}$ landslide movement is very nonuniform, which is closely related to soil weathering. The XJ landslide movement undergoes periodic acceleration. We deduce that the motion of the landslide may be affected by precipitation and water level fluctuation and indicate that the combination of precipitation and water level fluctuation is the most serious triggering factor. During the period from August to September, the rate of landslide movement reached a peak value, which was highly consistent with the precipitation and water level records. Additionally, the rescaled range method $(\mathrm{R} / \mathrm{S})$ is used to analyze the stability of the XJ landslide. The results show that hydrological conditions are an essential factor in the stability of the landslide. In other words, the more precipitation there is, the larger the water level changes and the more unstable the landslide.
\end{abstract}

\section{Introduction}

In recent years, the Jinsha River has been extensively developed for hydroelectric power generation, and the Chinese government has planted 27 hydropower stations along the Jinsha River [1]. There are eight small- and medium-sized hydropower stations along the middle reaches of the Jinsha River in Yunnan Province [2]. Ahai hydropower station (AHHs) and Liyuan hydropower station (LYHs) are two such medium-sized hydropower projects [2, 3]. When AHHs began to impound in January 2012, the water level near the research area rose rapidly from $1489 \mathrm{~m}$ to the design water level of $1504 \mathrm{~m}$ in six months. A rapid water level rise can threaten the safety of the hydropower station and local residents $[1,2,4,5]$. Therefore, monitoring landslide movement and analyzing landslide stability are extremely important $[5,6]$. Traditional methods for monitoring landslides include crack monitoring, GPS, and total station [7]. These methods reflect the landslide movement by recording the relative and absolute deformation of monitoring points. Although the accuracy of those monitoring methods is relatively high, their spatial resolution is limited by the number and distribution of the monitoring points [8]. This makes them more suitable for local high-precision landslide monitoring than for reflecting the overall deformation characteristics of large-scale landslide movement. In recent years, the development of remote sensing technologies gives us offer chances to detect and 


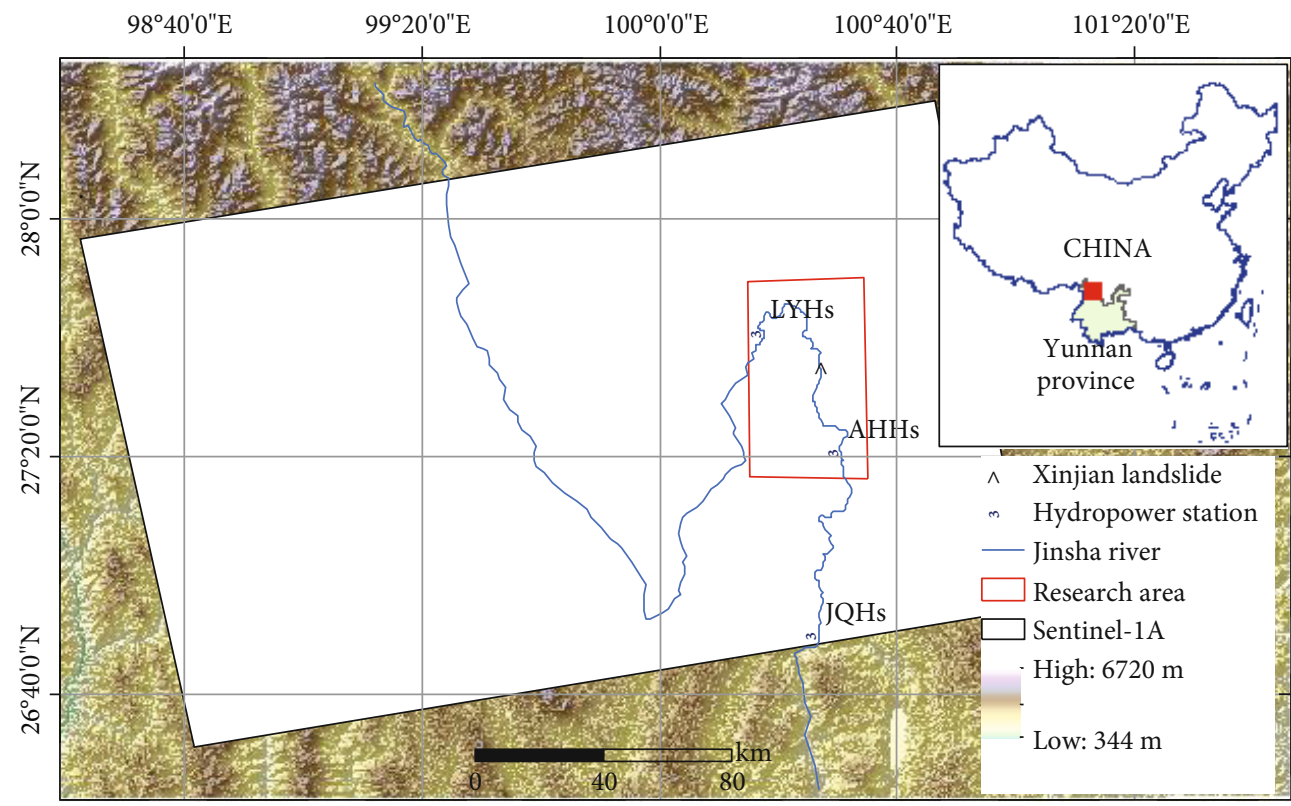

FIgURE 1: The study area location and SAR data coverage. The background is the shaded topography generated from the shuttle radar topography mission digital elevation model (SRTM DEM). The inset indicates the study area location in China.

monitor landslides in a wider scope. Ground-based devices such as ground-based InSAR (GB-InSAR) [9] and terrestrial laser scanning (TLS) [10] can accurately identify and monitor deformation of a few millimeters in a short time. However, their effective monitoring rang may be limited due to topography constraints. In addition, ground-based devices do not even work in some dangerous mountain areas. Comparatively, the monitoring range and accuracy of airborne remote sensing technologies (such as airborne unmanned aerial vehicle (UAV) photogrammetry [11]) are between the spaceborne and ground-based devices; the flexibility and high adaptability to complex terrain make it a vital way to obtain high-quality data. Airborne UAV achieves high-precision observation mainly by deploying a large number of ground control points (GCPs). Their number and distribution determine the quality of UAV data [11]. However, in valleys, mountains, and dangerous disaster areas, it is sometimes unfeasible to set up sufficient manual GPSs in the study area. Besides, airborne remote sensing technologies are difficult to obtain data in the dark or bad weather. Among the advance remote sensing technologies, spaceborne SAR cannot match the spatial detail or time resolution achievable by means of airborne or groundbased devices. Nevertheless, spaceborne SAR owes to its high precision, high-spatial resolution, broad coverage, and operation under all weather conditions, and it has been proved to be effective in large-scale landslide hazard identification, deformation monitoring, and landslide stability analysis $[1,8]$.

The time series InSAR (TS-InSAR) techniques are extensively used for landslide investigation and identification [12], landslide monitoring and mapping [13, 14], and stability assessment of landslides [15, 16]. Persistent scatterer interferometry (PSI) and distributed scatterer interferometry (DSI) are two main categories of TS-
InSAR [17]. PSI takes a single-reference strategy and extracts persistent scatterers (PS) to build deformation models for accurate analysis with multiple SAR images. However, it is difficult for PSI to obtain enough measurement points (MPs) in nonurban areas. In particular, in mountain areas, the density of PS points is usually less than 10 points $/ \mathrm{km}^{2}$ [18]. DSI employs distributed scatterers (DS), which usually correspond to the pixels whose neighboring pixels share similar reflectivity values, such as bare soil, sparsely vegetated land, or desert areas, which are typically found in rural environments and can significantly increase the spatial density of MPs in mountain areas [19, 20]. In our work, DS-InSAR is used to jointly process PS and DS targets to monitor ten ancient landslides located along the Jinsha River between the AHHs and LYHs; the distance between AHHs and LYHs is only $60 \mathrm{~km}$. Sentinel-1A data cannot monitor landslide movement before 2014. Therefore, the GPS measurement is used as a comparison and supplement to monitor the historical movement of landslides [7, 21]. It not only verified the results of InSAR measurement but also offered the tracks of landslide movement before 2014. DS-InSAR measurement result shows that we focus on ten potential ancient landslides located along the Jinsha River between the AHHs and LYHs; four active landslides are identified with average movement rates ranging from -148 to $148 \mathrm{~mm} / \mathrm{yr}$. By comparing the DS-InSAR results and GPS measurement results, we find that they show high-level consistency. Besides, GPS measurement also illustrates that after the initial impoundment, six landslides have gradually stabilized since October 2015, while the others remain active.

For the XinJian (XJ) landslide between the AHHs and the LYHs, the DS-InSAR results reveal that the spatiotemporal distribution characteristics of the XJ landslide are 


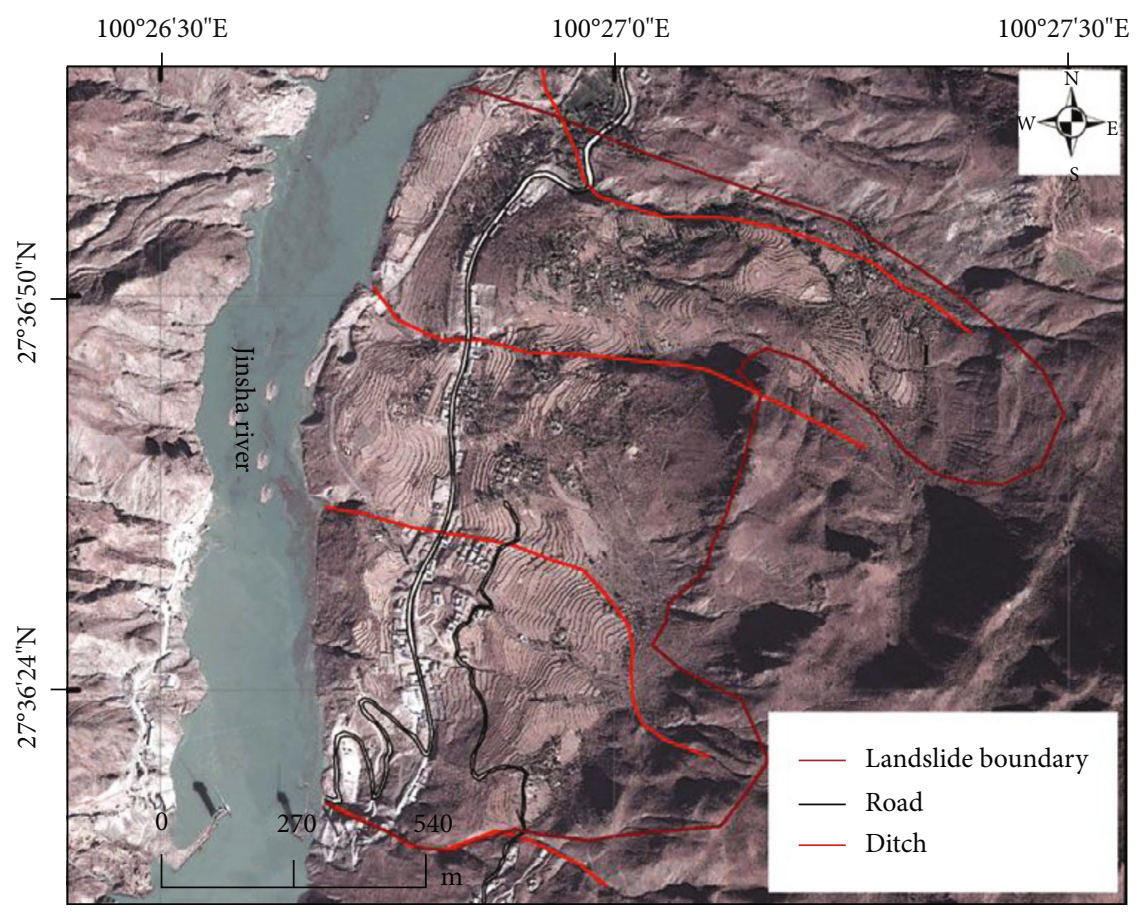

Figure 2: Overview of the XJ landslide from Google Earth image.

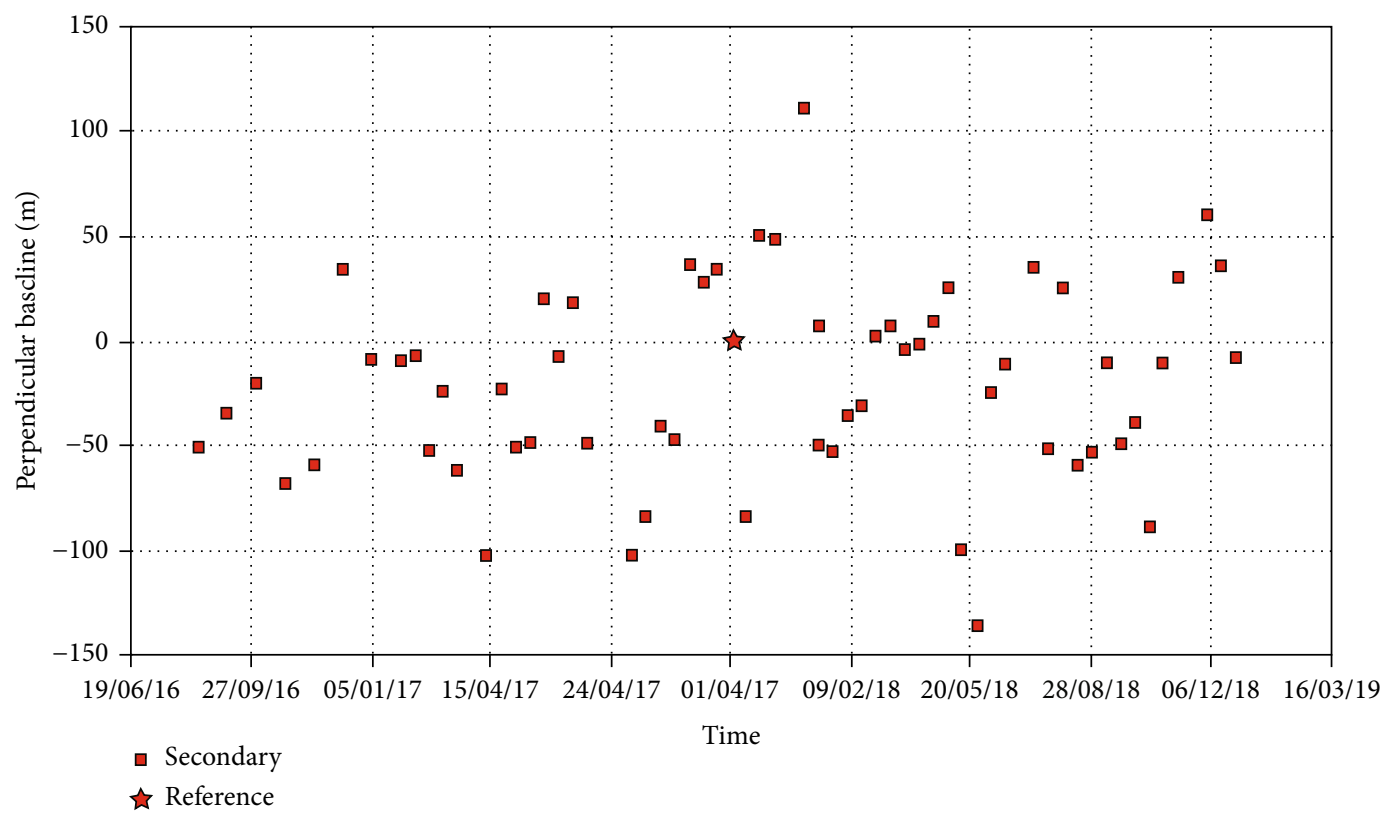

FIgURE 3: The full combination of interferometric pairs for Sentinel-1A datasets.

very complicated. The spatial distribution of landslide movement is very nonuniform. The landslide movement time series shows that the landslide movement undergoes periodic acceleration. However, we note that it remains unclear why the XJ landslide movement accelerated. Therefore, comprehensive analyses of the triggering factors were performed by combining landslide motion, monthly precipitation [22], water level change [1, 23], and soil weathering information from borehole data [24]. The result of analyses illustrates that the XJ landslide can be divided into three independent parts with totally different stabilities, which is closely related to factors such as the boundary of ditches and soil weathering. The data soil weathering is obtained by seventeen boreholes in the three different movement areas. In addition, the temporal distribution characteristics of the landslide show that its movement acceleration from May to February of the next year and the deformation are relatively low from February 


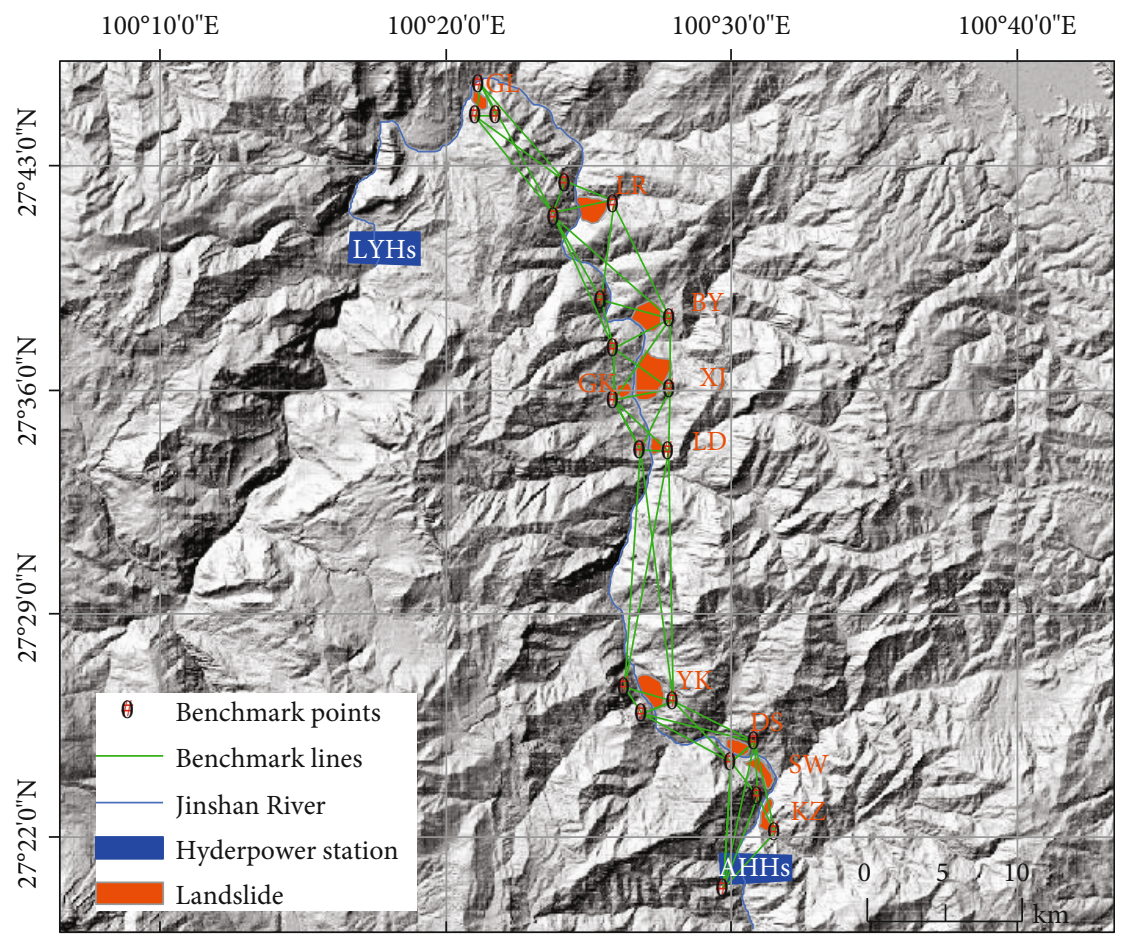

FIGURE 4: Landslide areas and GPS monitoring network distribution. The background is the hillshade topography generated from the shuttle radar topography mission digital elevation model (SRTM DEM).

to May with no obvious acceleration. We deduce that the deformation of the landslide may be affected by precipitation and water level fluctuation and find that the combination of precipitation and water level fluctuation is the most serious triggering factor.

In addition, landslide stability analysis is a prerequisite for the prevention of landslide hazards [25-27]. The rescaled range $(\mathrm{R} / \mathrm{S})$ method [28] is a time series analysis based on fractal theory. It is applied to analyze the stability of the XJ landslide. Nonparametric analysis algorithms rarely require an assumption regarding the study objects. Moreover, the method has good robustness, which makes it very suitable for the analysis of nonlinear time series of landslide deformation [29].

The main purpose of this paper is to monitor landslide movement along the Jinsha River and analyze the spatiotemporal movement characteristics. The results of DS-InSAR and GPS measurements show that four landslides are still active, and other landslides gradually stabilized after October 2015. For the XJ landslide, the fundamental cause of landslide movement was analyzed to better understand the acceleration of XJ landslide movement. In addition, we analyze the results of the R/S method to evaluate the stability of the movement of landslide. The result shows that the XJ landslide became more unstable in the rainy seasons and in periods of water level change. Finally, it is expected that the results of this study will provide theoretical support for the improvement of disaster prevention and risk mitigation measures in hydropower stations along the Jinsha River.

\section{Study Area}

A long reach, of approximately $60 \mathrm{~km}$, between the AHHs and LYHs was selected as the study area (Figure 1). The south bank of the study area is in Yulong County, while the north bank is in Ninglang County. The study area is located in the middle section of the Hengduan Mountains in northwestern Yunnan [30]. The terrain is high in the northwest and low in the southeast, and the depth of the valley generally ranges from 1480 to $1700 \mathrm{~m}$ [2]. In addition, this study area includes the Jinsha mountain canyon landform, which is affected by tectonic activity and river erosion. The northwest, southwest, and southeast sides of the study area are adjacent to the Songpan-Ganzi fold system, the Sanjiang fold system, and the Southern China fold system, respectively [31]. The AHHs reservoir area has been influenced by the strong activities of the western geosyncline and thus exhibits well developed folds and faults [2]. The bedrocks of the lower Simian system of the Neoproterozoic to Mesozoic Upper Cretaceous system and the Quaternary deposits in the Cenozoic are distributed in the study area. In addition, the hydrological conditions in the study area are complex and changeable, with abundant rainfall. Heavy rain is concentrated in July-October, accounting for $78 \%$ of the annual rainfall. After the rainy season, the hydropower station regulates the water level of the Jinsha River through reservoir flood discharge and water storage, which triggers a large number of landslides in the study area, thus increasing the associated hazard [32]. 


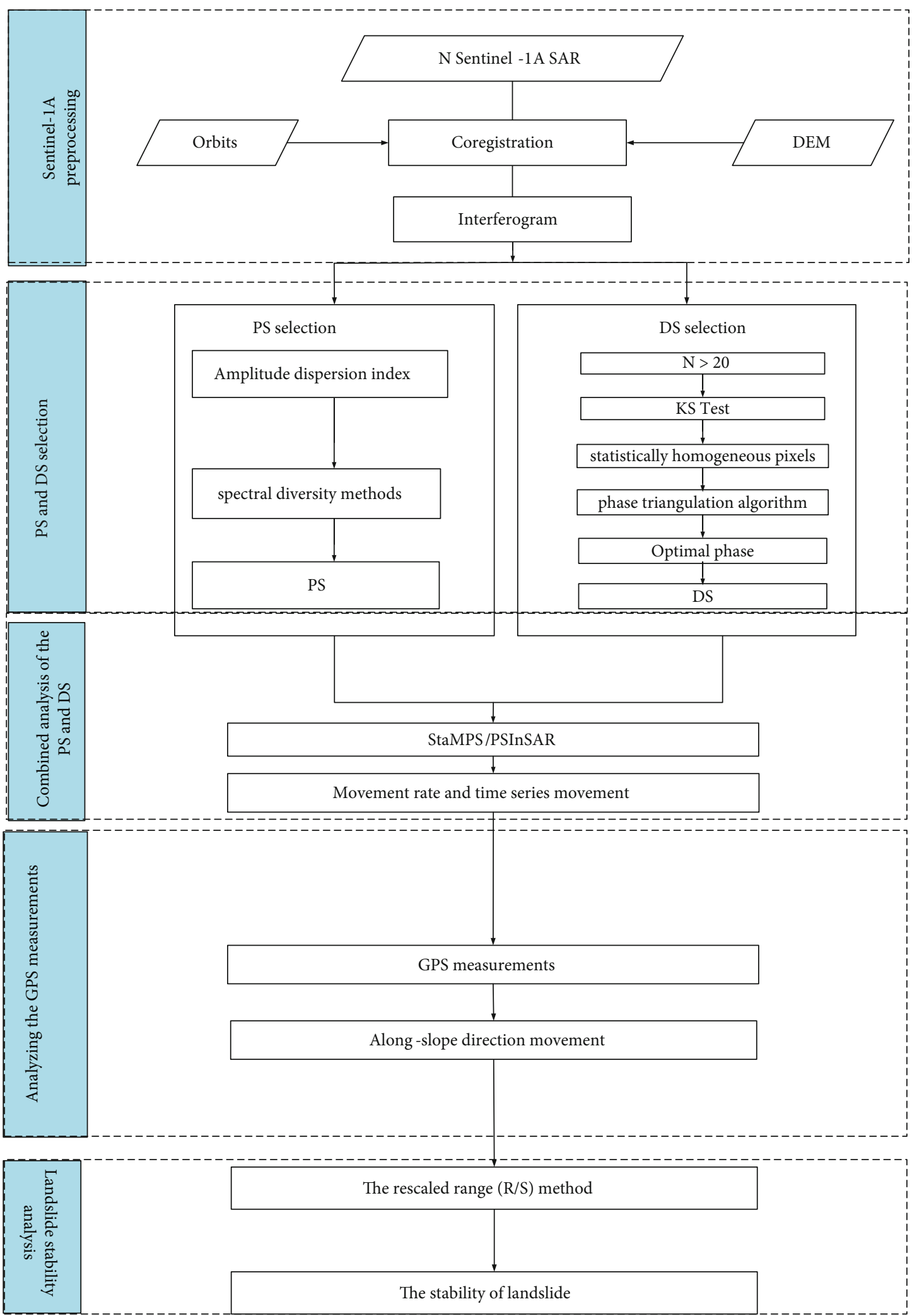

Figure 5: The flowchart of landslide identification, monitoring, and landslide stability analysis.

The XJ landslide, marked with a black pentacle in Figure 1, is located at the left side of the Jinsha River, approximately $37 \mathrm{~km}$ from the AHHs dam site. The land- slide is approximately $1000 \mathrm{~m}$ long and $600 \mathrm{~m}$ wide, with a high elevation range from 1500 to $1700 \mathrm{~m}$. Since reservoir impoundment, the landslide movement has been slowing. 
TABle 1: Specific parameters of Sentinel-1A TOPS data and XJ landslide topography.

\begin{tabular}{lcc}
\hline Parameters & Actual value & Average value \\
\hline Incidence angle $(\theta)$ & $40.20^{\circ}-42.48^{\circ}$ & $42.32^{\circ}$ \\
Slope orientation $(\alpha)$ & $82.70^{\circ}-82.74^{\circ}$ & $82.72^{\circ}$ \\
Aspect angle $(\delta)$ & $246^{\circ}-250^{\circ}$ & $248^{\circ}$ \\
Slope angle $(\beta)$ & $11^{\circ}-12^{\circ}$ & $11.5^{\circ}$ \\
\hline
\end{tabular}

Four ditches were distributed in the landslide area (Figure 2). According to geological investigations and field surveys, the lithology of this landslide mainly consists of basalt, siltstone, gravel, aleurite, and clay layers with a mean gradient of approximately $41^{\circ}$ [33]. Meanwhile, the landslide has been significantly eroded by weathering, resulting in a low-strength, high-compressibility layer easily softened by water [2].

\section{Materials}

3.1. SAR Data. Sixty-two C-band archived Sentinel-1A TOPS SAR images spanning the period from September 7, 2016, to December 26, 2018, with ascending tracks are included in this paper. The Sentinel-1A TOPS mode data consist of a series of bursts with mutual overlaps. They are suitable for large-scale landslide movement monitoring due to their short revisiting time (12 days, when Sentinel-1A sensors are active over the same area) and $250 \mathrm{~km}$ swath at a $5 \mathrm{~m} \times 14 \mathrm{~m}$ spatial resolution [19]. The use of Sentinel $1 \mathrm{~A}$ data is already widespread in landslide stability analysis, given the free access to the images and wide availability of interferometric techniques and algorithms [34]. A one arcsecond shuttle radar topography mission (SRTM) digital elevation map (DEM) with a pixel size of $30 \mathrm{~m}$ is adopted to remove the topographic phase. Precise orbit determination (POD) data are used for orbital refinement and phase reflattening. Figure 3 illustrates the full combination of all Sentinel-1A interferometric pairs for DS-InSAR. Among all the SAR images, one SAR image was selected arbitrarily as the reference image, and the other secondary images were resampled on the same reference grid [35].

3.2. GPS Data. To monitor the movement of ancient landslides in the study area, a GPS monitoring network was set up in February 2012 and includes eighteen GPS benchmarks and eighty-four GPS measurement points (MPs), forming the GPS monitoring network that covered all the landslide areas as shown in Figure 4. The orange areas indicate ten ancient landslide areas, which were identified by field survey and prior geological investigation, marked as the KuZhi (KZ) landslide, ShaWei (SW) landslide, DongSha (DS) landslide, YanKe (YK) landslide, LaDing (LD) landslide, GuKong (GK) landslide, XJ landslide, BaiYa (BY) landslide, LaRi (LR) landslide, and GeLi (GL) landslide, which were distributed over the study areas. All GPS benchmarks were outside the landslide areas, where they were assumed to be stable. At least two GPS MPs were deployed in each landslide area, among which 15 GPS MPs were deployed in the
XJ landslide area. The GPS results were collected from October 2012 to December 2018, and the monitoring data were processed once a month in the rainy season and once a quarter in other periods, i.e., in March, June, July, August, September, and December, to include all the acquisition times of the Sentinel-1A datasets.

\section{Methodology}

DS-InSAR was applied to monitor the XJ landslide by combining PS and DS data. The processing flowchart shown in Figure 5 mainly consists of five steps: (1) Sentinel-1A preprocessing, including coregistration and interferometric. (2) PS and DS selection, where the Kolmogorov-Smirnov (KS) test is employed to select statistically homogeneous pixels, and then reconstruction of the optimal phases of DS via the phase triangulation algorithm. (3) Combined analysis of the PS candidates and DS candidates. Here, the StaMPS/ PSInSAR [36] processing program was used to retrieve the movement rate and time series movement. (4) Analyzing the GPS measurements, including GPS movement and line of sight (LOS) projection in the along-slope direction. (5) Landslide stability analysis. The R/S method was applied to analyze the stability of landslides. In the following sections, each of the five steps was explained in detail.

4.1. Sentinel-1A Preprocessing. The Sentinel-1A images were imported and coregistered by using free Doris software [37]. Meanwhile, the basic interferometric processing steps are also performed, such as multilook processing, intensity map generation, and DEM generation and geocoding.

4.2. PS and DS Sections. The amplitude dispersion index $D_{A}$ and spectral diversity methods are adopted to extract PS candidates, and their original phase values are used for further time series analysis [38]. As shown on the left side of the processed PS and DS sections in Figure $5, D_{A}$ is defined as follows [39]:

$$
D_{A}=\frac{\sigma_{A}}{\mu_{A}},
$$

where $\mu_{A}$ and $\sigma_{A}$ are the mean and standard deviation of a series of amplitude values for one pixel, respectively. Only the pixels with $D_{A}$ under a given threshold (typically $<0.4$ ) are considered PS candidates [40, 41].

Consider the distribution function of SAR intensity images with a long tail $[20,42]$. The Kolmogorov-Smirnov (KS) test is used to extract the statistically homogeneous pixels as DS candidates. The KS test is carried out on the backscatter intensity vectors of the central pixel and all pixels within a $15 \times 15$ estimation window to determine whether they share the same or similar statistics at a given significance level (0.95 in this step).

For $N$ coregistered multitemporal single-look complex (SLC) images, after identification of statistically homogeneous pixels for each DS candidate pixel, the optimal phase series of the DS pixel, $\theta=\left[\theta_{1}, \theta_{2}, \cdots, \theta_{N}\right]^{\mathrm{T}}$, can be estimated using the coherence matrix with the identified statistically 


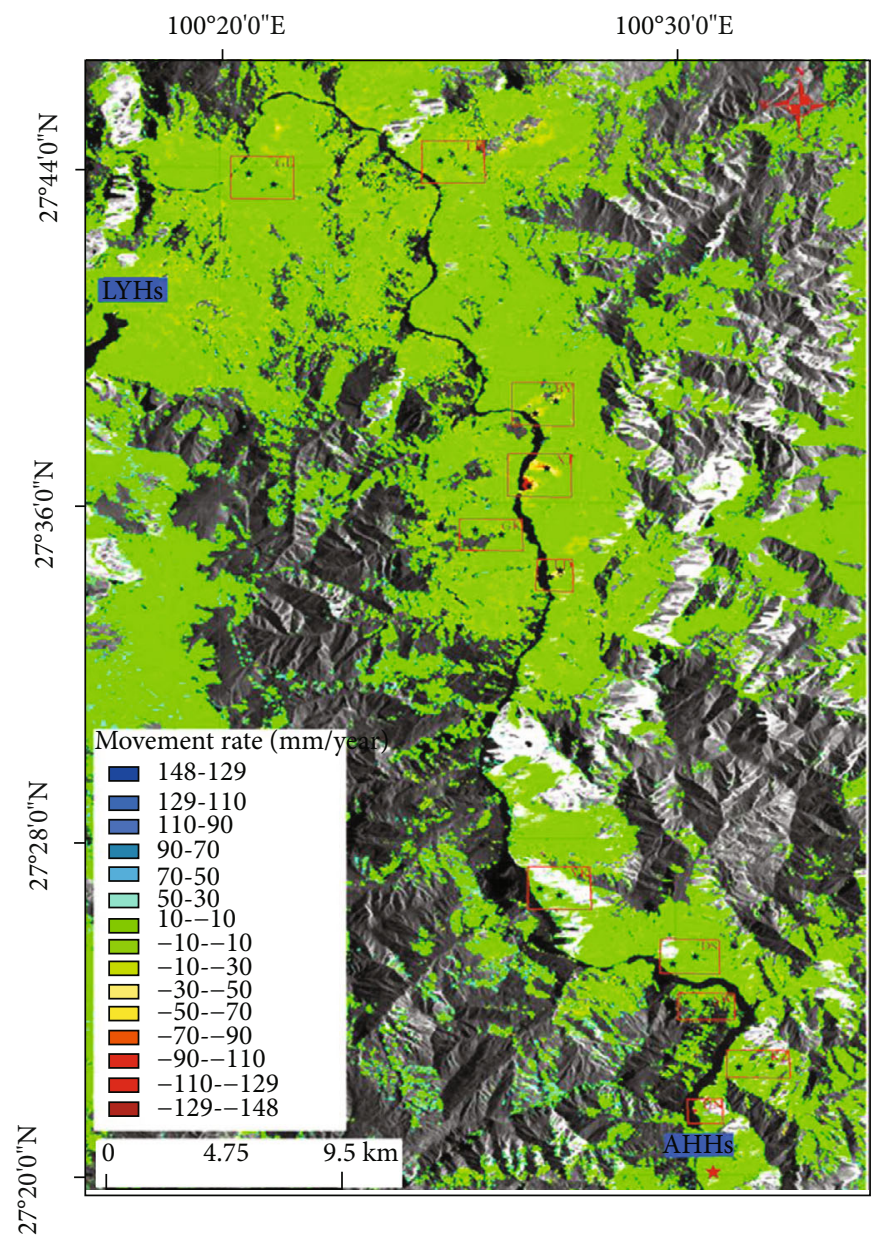

FIgURE 6: The LOS movement rates of the study areas from Sentinel-1A measured by DS-InSAR.

homogeneous pixels. The phase triangulation algorithm [35] was adopted to optimize the DS phase, and the adaptive space filtering method was used to improve the coherence of the interferogram. Without loss of generality, we set the first value of $\theta$ to zero, i.e., $\theta_{1}=0$. The maximum likelihood estimation of $\theta$ was computed as follows:

$$
\widehat{\theta}=\underset{\theta}{\operatorname{argmax}}\left\{\left|\eta^{H}\right|\left(-|T|^{-1} \circ T\right) \eta\right\},
$$

where $\widehat{\theta}$ is the estimated optimal phases, $H$ indicates the Hermitian conjugation, and the symbol $\circ$ is the Hadamard product. $\eta=\left[0, e^{i \theta_{2}}, \cdots, e^{i \theta_{N}}\right]^{\mathrm{T}}, i \leq N$, and the symbol $T$ represents the $N \times N$ coherence matrix for each statistically homogeneous pixel. A phase linking approach [20] is adopted to solve the maximum likelihood estimation problem as explained by SqueeSAR ${ }^{\mathrm{TM}}[17,43]$. This phase estimation method efficiently filters the decorrelation phase noise and preserves detailed spatial information [44]. After the optimal phases are estimated, the final DS candidates are selected according to the goodness-of-fit index $\gamma_{\text {PTA }}$. The quality of the estimated optimal phase can be determined by the goodness-of-fit formulated as follows:

$$
\gamma_{\mathrm{PTA}}=\frac{2}{N(N-1)} \operatorname{Re} \sum_{n=1}^{N} \sum_{k=n+1}^{N} e^{i \phi_{n k}} e^{-i\left(\theta_{n}-\theta_{k}\right)},
$$

where $\phi_{n k}$ is the phase value of the element at row $n$ and column $k$ of the coherence matrix and $\theta_{n}$ and $\theta_{k}$ are the estimated optimal phases. The DS candidates were weeded further according to $\gamma_{\mathrm{PTA}}$. DS candidates with a $\gamma_{\mathrm{PTA}}>$ 0.65 are kept.

4.3. Combined Analysis of PS and DS. The PS candidates and DS candidates were jointly processed using a standard StaMPS/PSInSAR tool with Doris software. Here, the PSInSAR processing program drops DS pixels that coincide with PS pixels. All PS and DS pixels were connected to form the Delaunay triangulation network for phase analysis. The phase was first corrected for the spatially uncorrelated part of the look angle error due to the DEM error and pixel phase center uncertainty. 3D phase unwrapping was then implemented to unwrap the interferometric phase in temporal and spatial dimensions [45]. Optionally, the unwrapped phases can be filtered by a high-pass filter in time and a low-pass filter in space to estimate the remaining spatially correlated nuisance terms, such as the atmospheric and orbital phases $[41,46]$. The MP density in the research area 

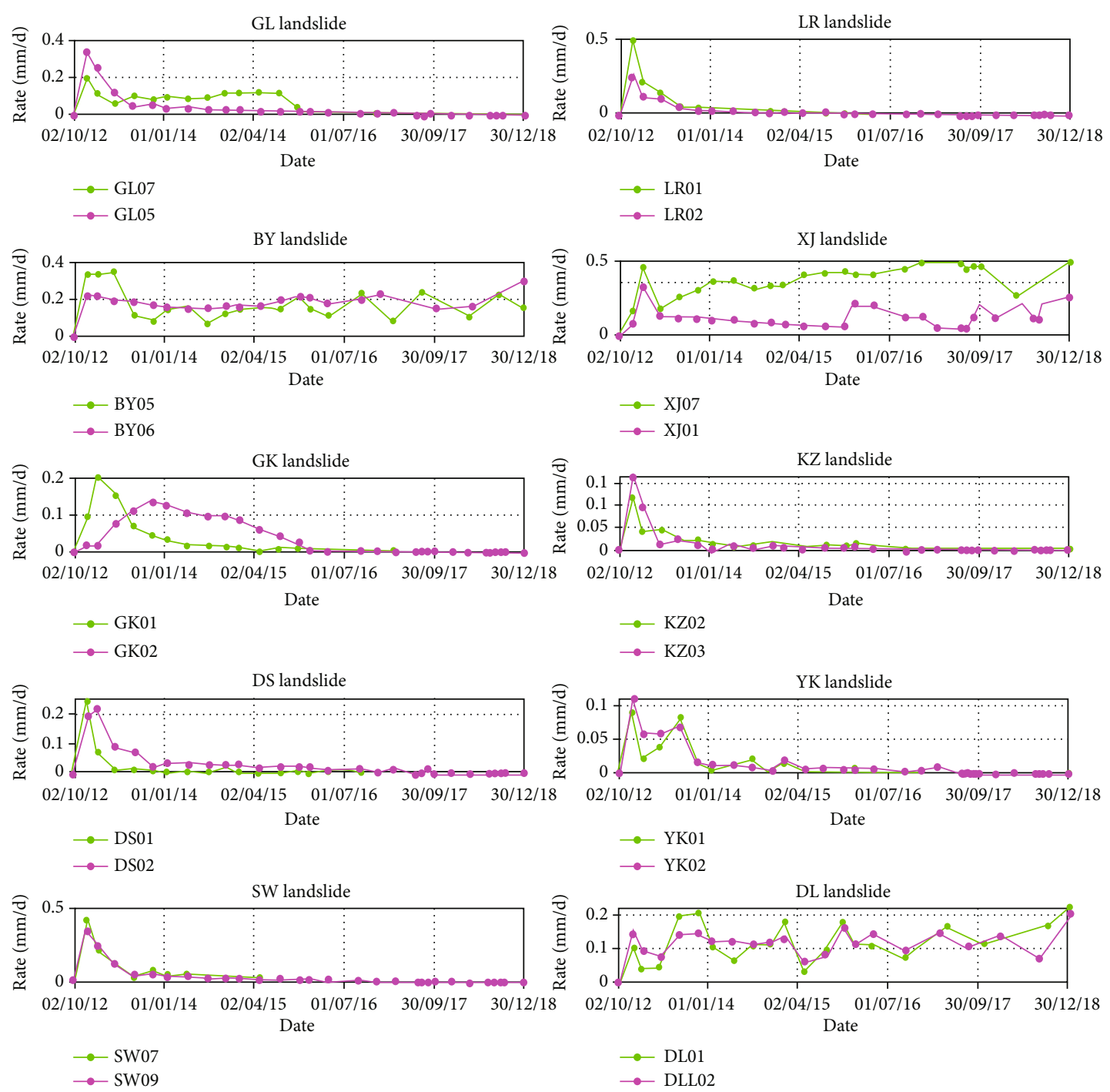

FIgURE 7: The GPS time series of ten ancient landslides.

was $2324 \mathrm{~km}^{-2}$, and data from the MPs were used to estimate the landslide movements. In the study area, according to a field survey and the GPS results, reference point $P$ was selected in the stable area near the hydropower station to retrieve the movement rate and time series movement.

4.4. GPS Measurements and Along-Slope Direction Movement. DS-InSAR technology provided the movement of landslides between 2016 and 2019 only. To monitor the historical movement of landslides in the study area, the GPS monitoring network setup in February 2012 was used. Dual-frequency Trimble 5700 GPS receivers with a $15 \mathrm{~s}$ interval were used. At the MPs, the observation time was longer than $6 \mathrm{~h}$. GAMIT/GLOBK software was employed to process the GPS observations. Finally, the GPS data were used to evaluate the results derived from DS-InSAR and analyze the landslide movement in the early stage of reservoir impoundment. Meanwhile, the GPS time series (from September 21, 2016, to December 31, 2018) were projected onto an independent coordinate system with the $x$-axis parallel to the along-slope direction and the $y$-axis perpendicular to the along-slope direction by coordinate transformation.

The InSAR data can measure the movement along only the LOS direction, which cannot directly reflect the actual movement of the landslide [15, 47]. The procedure for the projection of the LOS vectors is based on both geomorphological and DEM models [48-50]. The LOS movement was projected onto the along-slope direction using the following equation [49]:

$$
d_{\text {slope }}=\frac{d_{\mathrm{LOS}}}{\sin \theta \cdot \cos \alpha \cdot \sin \delta \cdot \cos \beta-\sin \theta \cdot \sin \alpha \cdot \cos \delta \cdot \cos \beta+\sin \beta \cdot \cos \theta},
$$

where $d_{\text {slope }}$ is the along-slope direction movement, $d_{\mathrm{LOS}}$ is the LOS direction movement, $\theta$ is the incidence angle with respect to the "flat earth," which is the angle between the vertical direction and the radar LOS, and $\alpha$ is the slope 


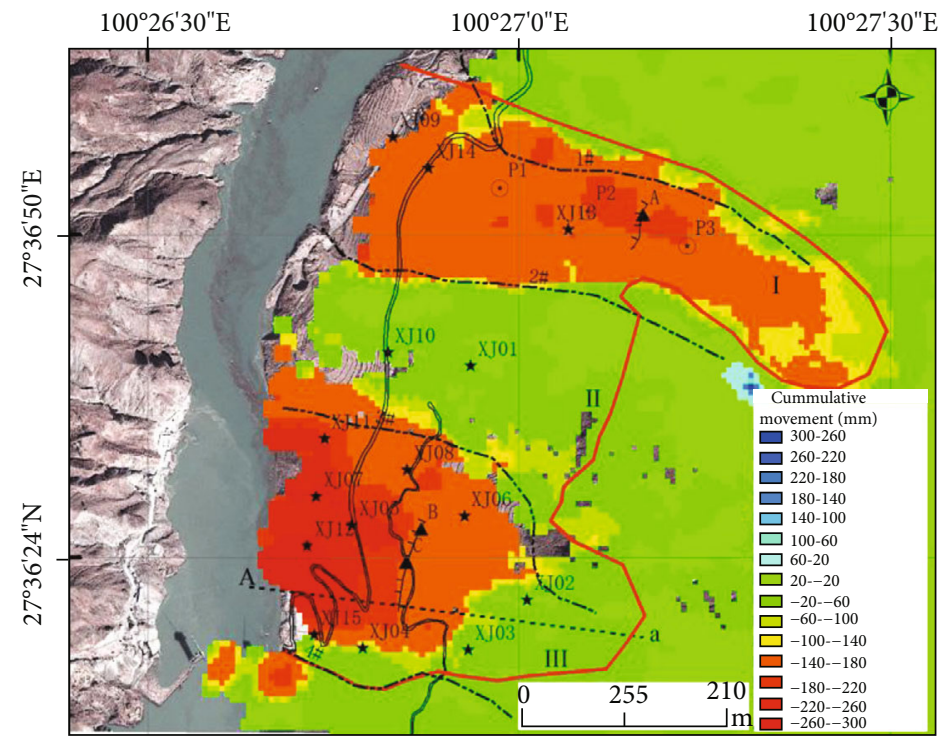

FIGURE 8: LOS movement over XJ landslide derived from DS-InSAR technology.

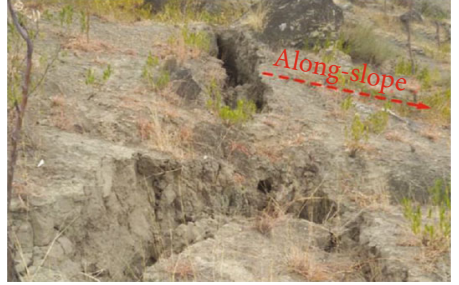

(a)

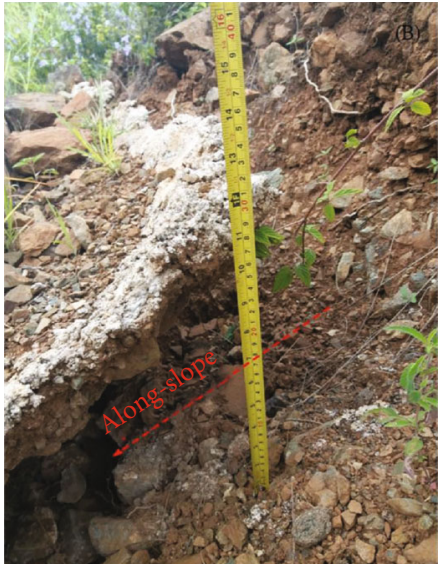

(b)

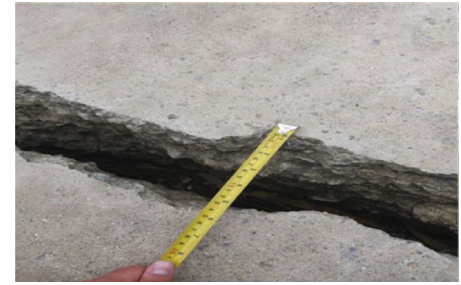

(c)

Figure 9: Photographs of 3 cracks extracted from Figure 8. The position of cracks ( $a, b$, and c).

orientation, which is the angle between the azimuth and north direction. $\delta$ is the aspect angle; $\beta$ is the slope angle.

According to the Sentinel-1A TOPS data and DEM models, the specific parameters of the Sentinel-1A and $\mathrm{XJ}$ landslide topographies are illustrated in Table 1.

The procedure for the projection of LOS movement vectors is based on the parameters of the Sentinel-1A and XJ landslide topography, and the projection formula is as follows:

$$
d_{\text {slope }}=\frac{d_{\mathrm{LOS}}}{0.176}
$$

4.5. The Stability of Landslide. The R/S analysis method was first proposed as a new statistical method by British scientist studying hydrological observational data of the Nile, then was improved by Mandelbrot and Wallis in theory, and finally was developed into fractal theory [29]. The
$\mathrm{R} / \mathrm{S}$ analysis method [1] was used to analyze the stability of landslides, which is different from traditional evaluation and prediction methods such as the finite element method, discrete element method, and Fukuzono method [51]. The $\mathrm{R} / \mathrm{S}$ analysis method considered not only the data at MPs but also the moving traces of the MPs. This allows more information from the results of the landslide movement to be revealed and a broader understanding of the movement history at different stages of landslide to be obtained. According to the R/S analysis theory [52], when the Hurst index $H=0.5$, the development processes are independent; when the Hurst index $H>0.5$, its $H$ index represents that the evolution trend of landslide stability is persistent. In that case, the larger the relative value of the $H$ index, the greater the slope stability; when the Hurst index is $0<H<0.5$, its $H$ index represents that the general trend of landslide stability evolution is antipersistent and that the landslide will eventually become 


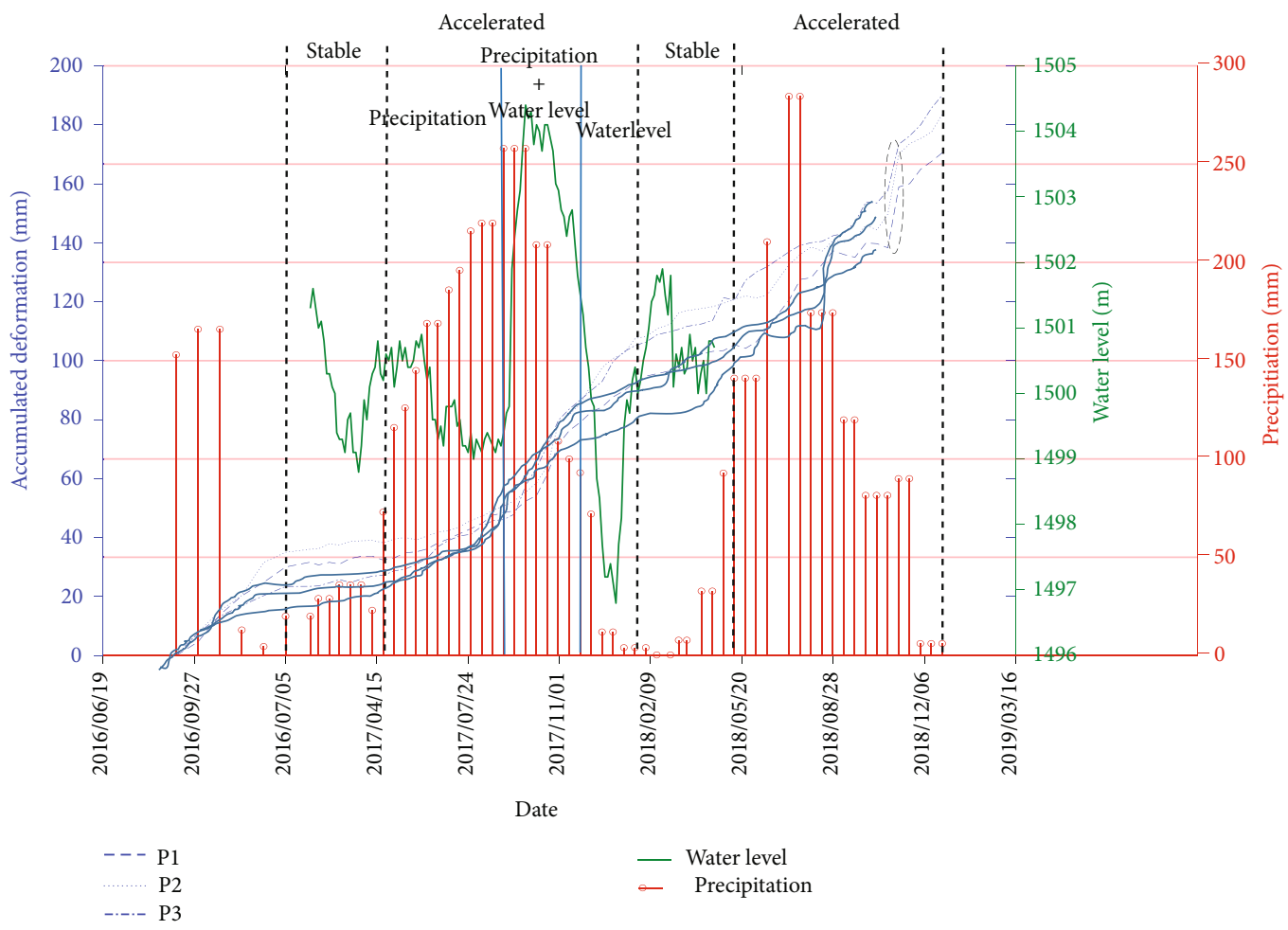

FIGURE 10: The relationship between InSAR cumulative movement derived from monitoring points P1, P2, and P3 (label in Figure 7) and precipitation and water level change.

TABLE 2: The triggering factors in different accelerated periods of XJ landslide.

\begin{tabular}{lcccc}
\hline Movement time & P1 & Movement rate $(\mathrm{mm} /$ year $)$ & P3 & Main triggering factors \\
\hline $2017.5-2017.8$ & 46.6 & 48.9 & 52.8 & Precipitation \\
$2017.8-2017.11$ & 133.4 & 150.9 & 176.4 & Precipitation and water level fluctuation \\
$2017.2-2018.2$ & 87.7 & 114.2 & 112.2 & Water level fluctuation \\
\hline
\end{tabular}

unstable. The smaller the relative value of the $H$ index is, the lower the landslide stability level and the greater the risk of landslide instability.

\section{Results and Analysis}

5.1. Landslide Movement Derived from DS-InSAR. The InSAR products including intensity maps and coherence maps and external DEM could be used to detect and map landslides that occur suddenly with a certain extent, while the deformation rate map is beneficial to identify the potential, slow, and long-term deformed landslides. In our experiment, four slow-moving landslide areas with movement rate exceeding $30 \mathrm{~mm}$ /year, along Jinsha River of approximate $60 \mathrm{~km}$, are identified from the InSAR deformation rate map. Four landslides marked as BY, XJ, LR, and UN, as shown in Figure 6. These landslides were ancient landslides, and other ancient landslides were not identified. These landslide movement rates along the radar line of sight (LOS) range from $-148 \mathrm{~mm} /$ year to $148 \mathrm{~mm} /$ year, and the maximum movement occurred in the XJ landslide area with a movement rate of $-148 \mathrm{~mm} /$ year. As the deformation is illuminated in Figure 6, please note that the blue and red distribution indicates the landslide movement along the LOS toward and away from the radar, respectively. Red rectangles represent the ancient landslide areas were identified by geological investigation and filed survey, the blue rectangle represents the location of the LYHs and the AHHs, and the black pentagon represents the geographical position of GPS monitoring points. The red pentagon represents the InSAR movement reference point $P$.

5.2. Landslide Movement Derived from GPS. At least two GPS MPs were arranged on each landslide body. The movement time of the two GPS MPs was long, and the accumulation of movement was large. Therefore, two GPS MPs with significant movement were selected to represent the overall movement state of each landslide body. Figure 7 shows the time series movement rate of two selected GPS MPs. We infer that in the initial stage of water storage of the reservoir at AHHs on January 12, 2012, the water level near the research area rose rapidly from $1489 \mathrm{~m}$ to the 
TABLE 3: Comparison between GPS measurements and DS-InSAR results.

\begin{tabular}{lcccl}
\hline MPs & $\begin{array}{c}\text { InSAR along-slope } \\
\text { cumulative } \\
\text { movement }(\mathrm{mm})\end{array}$ & $\begin{array}{c}\text { GPS along-slope } \\
\text { cumulative } \\
\text { movement }(\mathrm{mm})\end{array}$ & $\begin{array}{c}\Delta \\
(\mathrm{mm})\end{array}$ & $\begin{array}{c}\text { RMSE } \\
(\mathrm{mm})\end{array}$ \\
\hline XJ01 & 12.4 & 20.7 & -8.3 & \\
XJ02 & 531.4 & 549.3 & -17.9 & \\
XJ03 & 638.4 & 602.6 & 35.8 & \\
XJ04 & 1102.3 & 1051.4 & 50.9 & \\
XJ05 & 942.1 & 919.1 & 23 & \\
XJ06 & 768.3 & 762 & 6.3 & \\
XJ07 & 965.3 & 925.7 & 39.6 & \\
XJ08 & 623.4 & 613.5 & 9.9 & \pm 39.8 \\
XJ09 & 287.3 & 302.1 & -14.8 & \\
XJ10 & 18.8 & 23.6 & -4.8 & \\
XJ11 & 727.2 & 759.1 & -31.9 & \\
XJ12 & 1652.3 & 1739.4 & -87.1 & \\
XJ13 & 421.2 & 409.4 & 11.8 & \\
XJ14 & 352.3 & 331.6 & 20.7 & \\
XJ15 & 1312.1 & 1407.3 & -95.2 & \\
\hline
\end{tabular}

design water level of $1504 \mathrm{~m}$ over six months, which may have caused ten ancient landslide revival. Among them, the GL, LR, GK, YK, DS, SW, and KZ landslides gradually stabilized after October 2015, and others are still active now.

5.3. The Spatiotemporal Analysis of a Landslide. Figure 8 shows that the spatial characteristics of the XJ landslide movement were very uneven and that this landslide can be divided into three independent parts with totally different stabilities from the four ditches, namely, areas I, II, and III. These ditches are basically distributed in the east-west direction, which can affect the spatial distribution of the movement of landslides. Please note that the blue in Figure 8 indicates the movement toward the sensor, while the red is away from the sensor. The solid red line represents the boundary of the landslide. The black dots represent the four trenches $1 \#, 2 \#, 3 \#$, and $4 \#$. The blue dotted line represents the geological structure profile of the A-a line. The black double solid line represents the national secondary highway. The black fence line represents the landslide crack area. Among them, photographs in Figures 9(a), 9(b), and 9 (c) were taken in the black triangle positions. The black pentagon marks represent the GPS monitoring points, and InSAR movement is extracted at the position marked with black circled asterisk at symbols P1, P2, and P3.

Figure 10 shows the relationship between InSAR cumulative movement and precipitation and water level change. Monthly precipitation data from 2016 to 2018 were collected from the China Weather Network (http://www .weather.com.cn/) [22]. Besides, from February 2017 to April 2018, water level data were collected daily by the Ninglang County meteorological station near the study area, and unfortunately, we are missing water level data after 2018. However, the changes in the water level and precipitation were similar each year during the monitoring period $[33,53]$. The rainfall was mainly concentrated from June to November, and the change in the water level was mainly concentrated from August to February of next year. From Figure 10, we find that the XJ landslide underwent periodic acceleration from 2016 to 2018. The movement of the landslide can be divided into stable and accelerated periods. The cumulative movement increased slowly in the stable period from February to May every year, while the cumulative movement increased rapidly in the accelerated period from May to February of next year, and during this period, precipitation and water level fluctuations also increased. When the rate of landslide movement reaches the peak, the fluctuation of water level and rainfall also reaches the maximum. We deduce that the periodic acceleration of landslide movement is closely related to precipitation and water level fluctuation. Therefore, through the analysis of the graph in Figure 10, we clearly sorted out the relationship of them as shown in Table 2. Table 2 shows that the triggering factors offered different contributions to landslide movement in different accelerated periods. It is clear that the combination of precipitation and water level fluctuation has the greatest effect on landslide movement, followed by water level fluctuation and precipitation. The movement triggered by water level fluctuation is approximately double that caused by precipitation. In addition, the dashed ellipse in Figure 10 represents the period from November 6, 2018, to November 28, 2018, when the landslide movement exceeded $22 \mathrm{~mm}$ in just 22 days. We infer that the sudden acceleration of landslide movement may be related to the occurrence of $3.2 \mathrm{M}_{\mathrm{w}}$ earthquake on November 5, 2018, in Lijiang City. The data of earthquake were collected from the Yunnan Earthquake Prevention and Disaster Reduction (http://www.yndzj.gov.cn/yndzj/syl/index.html). The XJ landslide is about $30 \mathrm{~km}$ away from the epicenter.

\section{Comparisons and Discussions}

6.1. Comparison of DS-InSAR Results Using GPS Measurements. We performed comparisons of the landslide cumulative movement on the XJ landslide determined from Sentinel-1A data and GPS data. Figure 9 shows that there are cracks on the surface of the XJ landslide. Clearly, the red arrow in Figure 9(a) and Figure 9(b) indicates the along-slope direction of the landslide movement. We took Figure 9(a) from the left of the landslide and Figure 9(b) from the right of the landslide. Therefore, in the following analysis, the movement along the slope direction was mainly considered. The LOS movement was projected onto the along-slope direction by using Equation (5). In addition, the GPS measurements were projected onto the along-slope direction described in the GPS measurement section. For each GPS monitoring station, all the Sentinel-1A MPs located near the GPS station within a horizontal distance of $\leq 50 \mathrm{~m}$ were selected to enable the comparison. We found that the differences in the cumulative movement results between DS-InSAR and GPS were as follows: the maximum difference $\Delta_{\max }$ was 


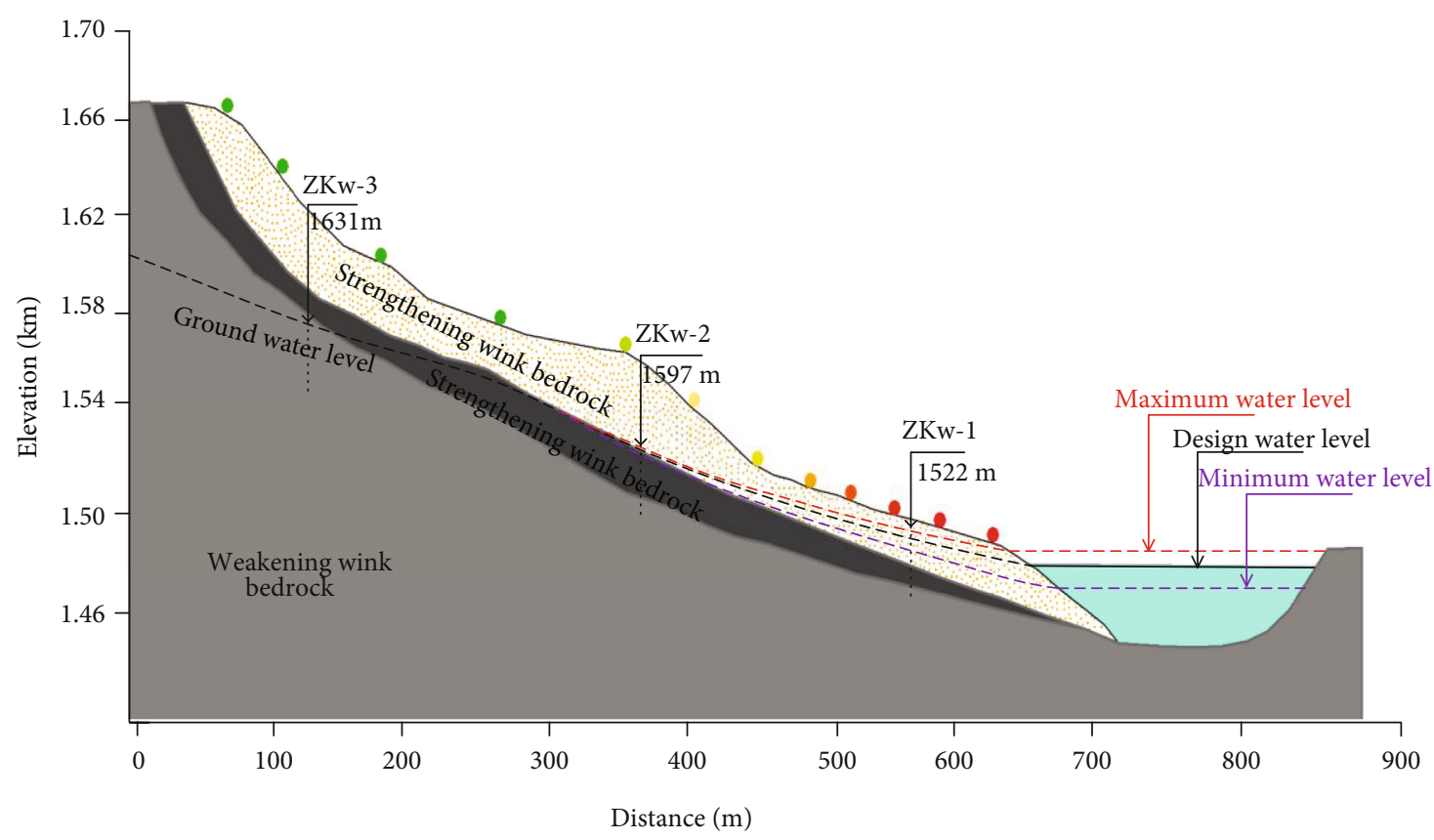

Cummulative movement $(\mathrm{mm})$
$\square 300-260$
$\square 260-220$
$\square 220-180$
$\square 180-140$
$\square 140-100$
$\square 100-60$
$\square 60-20$
$\square 20--20$

$$
\begin{aligned}
& \square-20--60 \\
& \square-60--100 \\
& \square-100--140 \\
& \square-140--180 \\
& \square-180--220 \\
& \square-220--260 \\
& \square-260--300
\end{aligned}
$$

Figure 11: Profiles of the geological structure as indicated by the A-a lines in Figure 7. ZKw-1, ZKw-2, and ZKw-3 represent the locations of boreholes at different elevations, which detect different depths of bedrock of the landslide and distributions of the groundwater level. The dot colors indicate LOS movement rates. "Weakening wink bedrock" and "strengthening wink bedrock" indicate the degree of weathering of the bedrock.

$95.4 \mathrm{~mm}$ (XJ15), the minimum difference $\Delta_{\min }$ was $6.3 \mathrm{~mm}$ (XJ06), and the root mean square error of the difference was $39.8 \mathrm{~mm}$ (Table 3). Besides, the cracks appear in the highway as shown in Figure 9(c), which indicates that the landslide movement has caused damage to infrastructure.

6.2. Analysis of the Triggering Factors of a Landslide. Landslide movement might be affected by various factors, including soil weathering, precipitation, and water level changes. Here, the major triggering factors and the $\mathrm{XJ}$ landslide movement are discussed. Soil weathering from seventeen boreholes in the three different movement areas, namely, areas I, II, and III, was collected.

Area III is the most serious movement area, with a maximum cumulative movement of $300 \mathrm{~mm}$ and a movement area of $0.26 \mathrm{~km}^{2}$. The lithology of this area mainly consists of basalt, siltstone, and clay layers, which are easily softened by water. Analyzing the data from six boreholes, we find that the surface soil and the bedrock of the landslides were seriously eroded by weathering and had strong water permeability and that the surface of the soil was loose. Therefore, the landslide easily moved under its own gravity and was softened by water immersion controlled by the hydrological stations.

Area $\mathrm{I}$ is the secondary movement area, with a maximum cumulative movement of $160 \mathrm{~mm}$ and a movement area of $0.38 \mathrm{~km}^{2}$. The lithology of this area mainly consists of siltstone, gravel, aleurite, and clay layers. According to the data from five boreholes, we find that the surface soil and bedrock of the landslide were weakly weathered. Under the action of water and gravity, the shear strength of the landslide body decreased, which also resulted in landslide movement.

The movement of area II is not obvious, with a cumulative movement smaller than $60 \mathrm{~mm}$ and a movement area of $0.27 \mathrm{~km}^{2}$. The lithology of this area is conglomerate. Meanwhile, according to the data from six boreholes, we find that the surface soil and bedrock of the landslides were not weathered, and the soil layer had lower water permeability than those in the other areas. Therefore, surface movement was not obvious in this area.

The XJ landslide has undergone persistent active movement and shown periodic acceleration characteristics, 


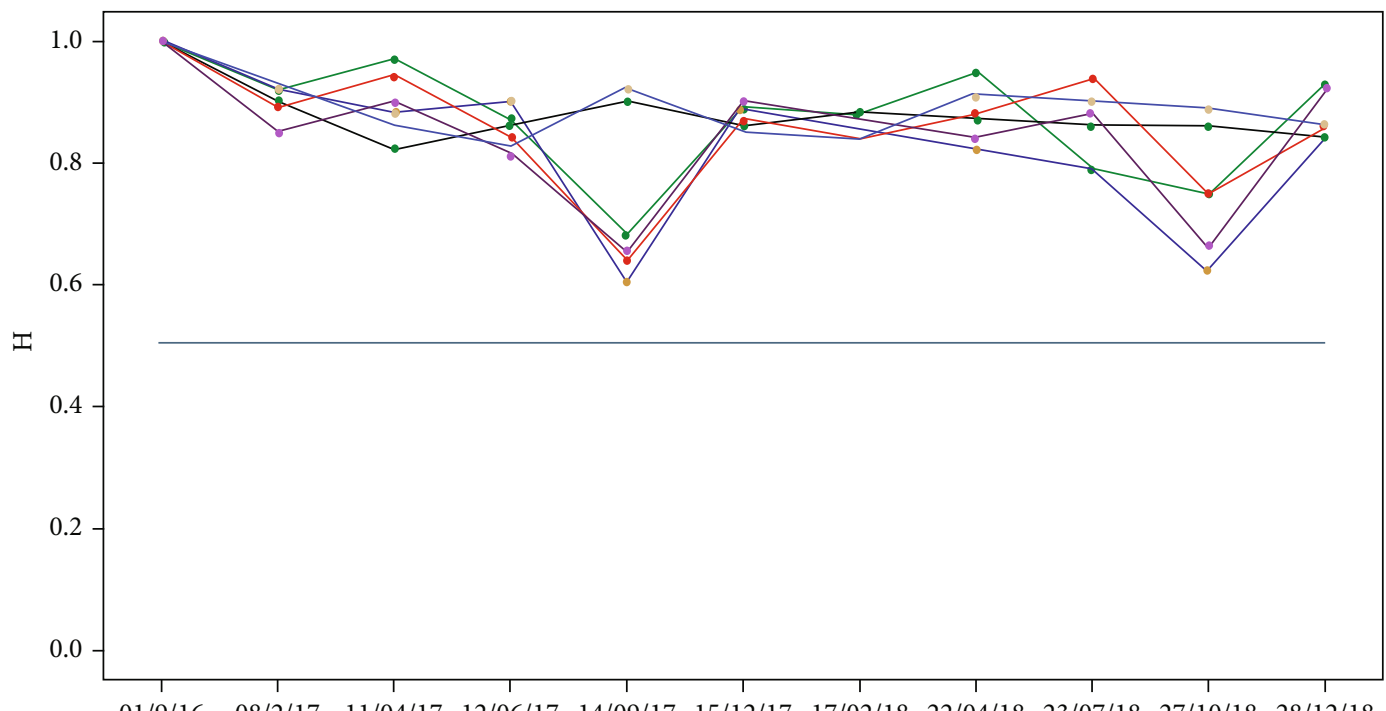

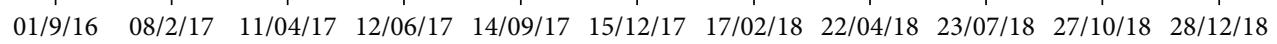

Date

$\begin{array}{lr}-\mathrm{XJ11} & -\mathrm{XJ} 09 \\ -\mathrm{XJ15} & -\mathrm{XJ14} \\ -\mathrm{XJ10} & -\mathrm{XJ11}\end{array}$

FIgure 12: The stability analysis chart of the R/S method of the XJ landslide. The light blue line is the dividing line of $H=0.5$ to judge whether the landslide is unstable.

which may be related to precipitation and Jinsha River water level changes, according to the sorting and analysis of the landslide movement and hydrological data. Figure 10 illustrates the relationship among precipitation, water level change, and cumulative movement extracted at MPs P1, P2, and P3. Some discussion can be drawn as follows:

(1) According to the data from three boreholes and geological data, the landslide groundwater level distribution was derived (Figure 11). The permeability of the landslide body between the groundwater level and the water level of the Jinsha River is very high, and the groundwater level changes with the water level change. From the dot colors in Figure 11, we infer that the closer the groundwater level is to the river, the more sensitive the groundwater is to water level change and the greater the triggered landslide movement is. It should also be noted that the water level of the Jinsha River has an important effect on the stability of a landslide. When the water level of the Jinsha River drops, the groundwater level around the landslide drops accordingly, and physically, the buoyancy force at the bottom of the landslide also decreases. At the same time, the groundwater in the landslide area is higher than that in the surrounding areas due to the inability to drain the pore water contained in the landslide, which reduces the antisliding ability while increasing the sliding force of the potential sliding blocks [28]. In other words, a drop in the Jinsha River water level aggravates the landslide movement rate. Under the repeated rise and fall of the water level of the Jinsha River, landslide movement shows periodic acceleration

During the rainy season, as rainwater penetrates the landslide, the clay eroded by weathering and limestone contains a large amount of water-swelling materials. When the clay is immersed in water and expanded, it not only increases the self-weight of the landslide body but also reduces the cohesion between particles, reduces or softens the shear strength of the landslide body, and produces disturbance. When the clay is disturbed and undergoes a higher strain, it stimulates greater pore water pressure of the clay and then accelerates the movement of the landslide body $[3,51]$.

6.3. Analysis of the Stability of the XJ Landslide. According to the above R/S method [28], the movement time series of the $\mathrm{XJ}$ landslide was processed. Because the time sampling rate of Sentinel-1A data (12 days apart) is shorter than that of GPS data (at least 1 month apart), Sentinel-1A data are more suitable for analyzing the stability of landslides. Therefore, six MPs were extracted from three independent parts of the XJ landslide with totally different stabilities, whose positions were coincident with or adjacent to GPS MPs, such as MPs XJ09 and XJ14 in area I, XJ01 and XJ10 in area II, and XJ11 and XJ15 in area III (label in Figure 8). By using the R/ $S$ method, the $H$ values of the landslide MPs were calculated every two months from September 2016 to December 2018. Figure 12 shows that the $H$ value of area II remained above 
0.8 , with small changes and a stable state. While the $H$ values of areas I and III decreased significantly from September 2018 to December 2018, they were less than 0.7. We find that storms and water level changes often occurred from October to December every year, when the $H$ value was less than 0.6. According to the rule of $H$ index changes, it is clear that the stability of areas I and III becomes more unstable from October to December. In other words, precipitation and water level changes can promote landslide instability.

\section{Conclusions}

The approach of landslide monitoring by DS-InSAR and GPS was presented. DS-InSAR technology jointly utilized PS candidates and DS candidates to increase the MP density of the study area. DS-InSAR technology has been successfully applied to monitor landslide movement in several study areas. The annual movement rate map in the LOS direction derived from DS-InSAR technology suggests that four landslides are present in the study area of this work, with average movement rates ranging from -148 to $148 \mathrm{~mm} /$ year. The maximum movement, with a movement rate of $148 \mathrm{~mm} /$ year, was located in the $\mathrm{XJ}$ landslide. In addition, the results of the GPS monitoring of landslide areas show that in the initial impoundment period of the AHHs, ten ancient landslides were reactivated: seven landslides gradually stabilized after October 2015, whereas the other three are active now. Comparisons were made between DS-InSAR and GPS results. We find that the DS-InSAR results are approximately consistent with the GPS results. The maximum cumulative movement difference and the minimum cumulative movement difference between these two sets of results in the XJ landslide area are $95.4 \mathrm{~mm}$ and $6.3 \mathrm{~mm}$, respectively. The spatiotemporal distribution of the $\mathrm{XJ}$ landslides is determined by combining the research results with soil weathering, precipitation, and water level change data. In addition, we infer that the spatial characteristics of the XJ landslide movement may be related to soil weathering. We also find that the XJ landslide underwent periodic acceleration and suggested that the motion of the landslide may be affected by precipitation and water level changes. To analyze the stability of the landslide, the R/S method was used to analyze the stability of different areas of the XJ landslide. The results showed that in the rainy season from July to October and in the period of water level changes from October to December, the XJ landslide areas III and I grew more unstable. The results of this study will provide theoretical support for the improvement of disaster prevention and risk mitigation measures in hydropower stations along the Jinsha River.

\section{Data Availability}

The authors thank the ESA for arranging the Sentinel-1A data, NASA for providing the SRTM DEM data, and the ESA for releasing the POD data.

\section{Conflicts of Interest}

The authors declare that they have no conflicts of interest.

\section{Authors' Contributions}

F.L. and Y.M. developed the idea that led to this paper. Y.M. and Z.W. contributed to the experimental implementation and analyses. Y.M. and J.A. interpreted the results. X.Z. and B.L. provided critical data and contributed to the final revision of the paper.

\section{Acknowledgments}

This work was supported by the National Natural Science Foundation of China (Grant No. 41776195 and No. 41531069). The authors thank the ESA for arranging the Sentinel-1A data, NASA for providing the SRTM DEM data, and the ESA for releasing the POD data.

\section{References}

[1] C. Zhao, Y. Kang, Q. Zhang, Z. Lu, and B. Li, "Landslide identification and monitoring along the Jinsha River catchment (Wudongde reservoir area), China, using the InSAR method," Remote Sensing, vol. 10, no. 7, pp. 993-1013, 2018.

[2] Z. Liu, Study on Bank Slope Stability of Dual Structure Reservoir under the Condition of Water Level Change, Kunming University of Science and Technology, 2017.

[3] Z. Zhou, M. Lin, Q. Guo, and M. Chen, "Scale effect and value criterion of the permeability of the interlayer staggered zones in the basalt of Jinsha River basin, China," Hydrogeology Journal, vol. 26, no. 5, pp. 1731-1748, 2018.

[4] N. Casagli, F. Catani, C. Del Ventisette, and G. Luzi, "Monitoring, prediction, and early warning using ground-based radar interferometry," Landslides, vol. 7, pp. 291-301, 2010.

[5] D. Peduto, G. Nicodemo, M. Caraffa, and G. Gullà, "Quantitative analysis of consequences to masonry buildings interacting with slow-moving landslide mechanisms: a case study," Landslides, vol. 15, pp. 2017-2030, 2018.

[6] G. Gullà, D. Peduto, L. Borrelli, L. Antronico, and G. Fornaro, "Geometric and kinematic characterization of landslides affecting urban areas: the Lungro case study (Calabria, Southern Italy)," Landslides, vol. 14, pp. 171-188, 2016.

[7] M. Komac, R. Holley, P. Mahapatra, H. van der Marel, and M. Bavec, "Coupling of GPS/GNSS and radar interferometric data for a 3D surface displacement monitoring of landslides," Landslides, vol. 12, pp. 241-257, 2014.

[8] N. Jiang, H. Li, Y. Hu et al., "A monitoring method integrating terrestrial laser scanning and unmanned aerial vehicles for different landslide deformation patterns," IEEE Journal of Selected Topics in Applied Earth Observations and Remote Sensing, vol. 14, pp. 10242-10255, 2021.

[9] A. Serrano-Juan, E. Vázquez-SuiE, O. Monserrat et al., GbSAR Interferometry Displacement Measurements during Dewatering in Construction Works, Case of La Sagrera Railway Station in Barcelona, Spain, 2016.

[10] N. Jiang, H. B. Li, and J. W. Zhou, "Quantitative hazard analysis and mitigation measures of rockfall in a high-frequency rockfall region," Bulletin of Engineering Geology and the Environment, vol. 80, no. 4, pp. 3439-3456, 2021.

[11] H. Huang, J. Long, H. Lin, L. Zhang, W. Yi, and B. J. E. S. I. Lei, "Unmanned aerial vehicle based remote sensing method for monitoring a steep mountainous slope in the Three Gorges 
Reservoir, China," Earth Science Informatics, vol. 10, no. 3, pp. 287-301, 2017.

[12] Q. Wu, H. Tang, X. Ma et al., "Identification of movement characteristics and causal factors of the Shuping landslide based on monitored displacements," Bulletin of Engineering Geology and the Environment, vol. 78, pp. 2093-2106, 2018.

[13] K. Dai, Z. Li, R. Tomás et al., "Monitoring activity at the Daguangbao mega-landslide (China) using Sentinel-1 TOPS time series interferometry," Remote Sensing of Environment, vol. 186, pp. 501-513, 2016.

[14] T. Luo, F. Li, B. Pan et al., "Deformation monitoring of slopes with a shipborne InSAR system_a case study of the Lancang River gorge," IEEE Access, vol. 9, pp. 5749-5759, 2021.

[15] X. Hu, Z. Lu, T. C. Pierson, R. Kramer, and D. L. George, "Combining InSAR and GPS to determine transient movement and thickness of a seasonally active low-gradient translational landslide," Geophysical Research Letters, vol. 45, pp. 1453-1462, 2018.

[16] L. Bao, X. Xing, L. Chen et al., "Time series deformation monitoring over large infrastructures around Dongting Lake using $\mathrm{X}$-band PSI with a combined thermal expansion and seasonal model," Journal of Sensors, vol. 2021, 17 pages, 2021.

[17] Z. Du, L. Ge, A. H.-M. Ng, Q. Zhang, and M. M. Alamdari, "Assessment of the accuracy among the common persistent scatterer and distributed scatterer based on SqueeSAR method," IEEE Geoscience and Remote Sensing Letters, vol. 15, pp. 1877-1881, 2018.

[18] K. Shirani and M. Pasandi, "Detecting and monitoring of landslides using persistent scattering synthetic aperture radar interferometry," Environmental Earth Sciences, vol. 78, no. 1, pp. 2-24, 2019.

[19] E. Intrieri, F. Raspini, A. Fumagalli et al., "The Maoxian landslide as seen from space: detecting precursors of failure with Sentinel-1 data," Landslides, vol. 15, pp. 123-133, 2017.

[20] J. Wang, C. Wang, C. Xie et al., "Monitoring of large-scale landslides in Zongling, Guizhou, China, with improved distributed scatterer interferometric SAR time series methods," Landslides, vol. 17, pp. 1777-1795, 2020.

[21] Y. Yin, W. Zheng, Y. Liu, J. Zhang, and X. Li, "Integration of GPS with InSAR to monitoring of the Jiaju landslide in Sichuan, China," Landslides, vol. 7, no. 3, pp. 359-365, 2010.

[22] M. Xia, G. M. Ren, S. S. Zhu, and X. L. Ma, "Relationship between landslide stability and reservoir water level variation," Bulletin of Engineering Geology and the Environment, vol. 74, pp. 909-917, 2014.

[23] M. Ciurleo, M. C. Mandaglio, and N. Moraci, “A quantitative approach for debris flow inception and propagation analysis in the lead up to risk management," Landslides, vol. 18, no. 6, pp. 2073-2093, 2021.

[24] W. Yao, C. Li, Q. Zuo, H. Zhan, and R. E. Criss, "Spatiotemporal deformation characteristics and triggering factors of Baijiabao landslide in Three Gorges Reservoir region, China," Geomorphology, vol. 343, pp. 34-47, 2019.

[25] D. Peduto, S. Ferlisi, G. Nicodemo, D. Reale, G. Pisciotta, and G. Gullà, "Empirical fragility and vulnerability curves for buildings exposed to slow-moving landslides at medium and large scales," Landslides, vol. 14, pp. 1993-2007, 2017.

[26] Y. Zhang, Z. Zhang, S. Xue, R. Wang, and M. Xiao, "Stability analysis of a typical landslide mass in the Three Gorges Reservoir under varying reservoir water levels," Environmental Earth Sciences, vol. 79, no. 1, pp. 42-56, 2020.
[27] X. Fan, C. J. van Westen, Q. Xu, T. Gorum, and F. Dai, "Analysis of landslide dams induced by the 2008 Wenchuan earthquake," Journal of Asian Earth Sciences, vol. 57, pp. 2537, 2012.

[28] T. Yang, N. Yang, and C. Zhu, "A new method of grain output prediction based on RS analysis," in International Conference on Advanced Material Science and Environmental Engineering 2016, pp. 234-237, Chiang Mai, Thailand, 2016.

[29] L. Weican and H. Lingli, "The study on fractal characteristics of television audience ratings based on RS analysis method," Management Science and Engineering, vol. 9, pp. 7-11, 2015.

[30] K. Shao, Y. F. Que, M. H. Xiong, W. T. Li, D. Yu, and F. Shi, "Length-weight and length-length relationships of thirteen fish species from the lower Jinsha River, Southwest China," Journal of Applied Ichthyology, vol. 34, pp. 774-776, 2018.

[31] Y. Cui, P. Bao, C. Xu et al., "A big landslide on the Jinsha River, Tibet, China: geometric characteristics, causes, and future stability," Natural Hazards, vol. 104, pp. 2051-2070, 2020.

[32] W. Yang, Y. Wang, S. Sun, Y. Wang, and C. Ma, "Using Sentinel-2 time series to detect slope movement before the Jinsha River landslide," Landslides, vol. 16, pp. 1313-1324, 2019.

[33] P. Wang, J. Chen, F. Dai et al., "Chronology of relict lake deposits around the Suwalong paleolandslide in the upper Jinsha River, SE Tibetan Plateau: implications to Holocene tectonic perturbations," Geomorphology, vol. 217, pp. 193-203, 2014.

[34] L. Zhou, J. Guo, J. Hu et al., "Wuhan surface subsidence analysis in 2015-2016 based on Sentinel-1A data by SBAS-InSAR," Remote Sensing, vol. 9, no. 10, pp. 982-1013, 2017.

[35] J. Dong, L. Zhang, M. Tang et al., "Mapping landslide surface displacements with time series SAR interferometry by combining persistent and distributed scatterers: a case study of Jiaju landslide in Danba, China," Remote Sensing of Environment, vol. 205, pp. 180-198, 2018.

[36] M. Rai and E. Simonetto, "PS-INSAR experiments for the analysis of urban ground deformation using StaMPS," in SPIE Europe Remote Sensing 2009 Conference, Berlin, Germany, 2009.

[37] A. Pumpuang and A. Aobpaet, "The comparison of land subsidence between east and west side of Bangkok, Thailand," Built Environment Journal, vol. 17, no. 3, pp. 1-12, 2020.

[38] P. Berardino, G. Fornaro, R. Lanari, and E. Sansosti, "A new algorithm for surface deformation monitoring based on small baseline differential SAR interferograms," IEEE Transactions on Geoscience and Remote Sensing, vol. 40, pp. 2375-2383, 2002.

[39] B. Mohamadi and T. Balz, "Measuring surface deformation in glacier retreated areas based on Ps-Insar - Geladandong Glacier as a case study," ISPRS - International Archives of the Photogrammetry, Remote Sensing and Spatial Information Sciences, vol. XLII-3, pp. 1285-1289, 2018.

[40] A. Ferretti, C. Prati, and F. Rocca, "Permanent scatterers in SAR interferometry," IEEE Transactions on Geoscience and Remote Sensing, vol. 39, pp. 8-20, 2001.

[41] S. Samiei-Esfahany, J. E. Martins, F. V. Leijen, and R. F. Hanssen, "Phase estimation for distributed scatterers in InSAR stacks using integer least squares estimation," IEEE Transactions on Geoscience \& Remote Sensing, vol. 54, pp. 1-17, 2016.

[42] A. Parizzi and R. Brcic, "Adaptive InSAR stack multilooking exploiting amplitude statistics: a comparison between different 
techniques and practical results," IEEE Geoscience and Remote Sensing Letters, vol. 8, pp. 441-445, 2011.

[43] S. Alberti, A. Ferretti, G. Leoni, C. Margottini, and D. Spizzichino, "Surface deformation data in the archaeological site of Petra from medium-resolution satellite radar images and SqueeSAR ${ }^{\mathrm{TM}}$ algorithm," Journal of Cultural Heritage, vol. 25, pp. 10-20, 2017.

[44] M. Jiang, X. Ding, R. F. Hanssen, R. Malhotra, and L. Chang, "Fast statistically homogeneous pixel selection for covariance matrix estimation for multitemporal InSAR," IEEE Transactions on Geoscience and Remote Sensing, vol. 53, pp. 12131224, 2015.

[45] A. Hooper, D. Bekaert, K. Spaans, and M. Arikan, "Recent advances in SAR interferometry time series analysis for measuring crustal deformation," Tectonophysics, vol. 514, pp. 1$13,2012$.

[46] J. Dong, J. Gong, M. Liao, L. Zhang, X. Shi, and Y. Liu, "Landslides analysis in western moutainous areas of China using distributed scatterers based InSAR," in 2016 IEEE International Geoscience and Remote Sensing Symposium (IGARSS), pp. 5773-5776, Beijing, China, 2016.

[47] W. Zhu, Q. Zhang, X. Ding et al., "Landslide monitoring by combining of CR-InSAR and GPS techniques," Advances in Space Research, vol. 53, pp. 430-439, 2014.

[48] P. Tantianuparp, X. Shi, L. Zhang, T. Balz, and M. Liao, "Characterization of landslide deformations in Three Gorges area using multiple InSAR data stacks," Remote Sensing, vol. 5, pp. 2704-2719, 2013.

[49] M. Akbarimehr, "Slope stability assessment of the Sarcheshmeh landslide, Northeast Iran, investigated using InSAR and GPS observations," Remote Sensing, vol. 5, no. 8, pp. 36813700, 2013.

[50] S. Plank, J. Singer, C. Minet, and K. Thuro, "Pre-survey suitability evaluation of the differential synthetic aperture radar interferometry method for landslide monitoring," International Journal of Remote Sensing, vol. 33, pp. 6623-6637, 2012.

[51] T. Fukuzono, "A method to predict the time of slope failure caused by rainfall using the inverse number of velocity of surface displacement," Landslides, vol. 22, no. 2, pp. 8-13_1, 1985.

[52] W. Y. Xu, Q. X. Meng, R. B. Wang, and J. C. Zhang, "A study on the fractal characteristics of displacement time-series during the evolution of landslides," Geomatics, Natural Hazards and Risk, vol. 7, pp. 1631-1644, 2015.

[53] Y. Chen, G. Zhang, and D. Chan, "Cyclic response and modeling of saturated silty clay due to fluctuations in reservoir water level of the Three Gorges Dam, China," Soils \& Foundations, vol. 58, no. 3, pp. 702-715, 2018. 